
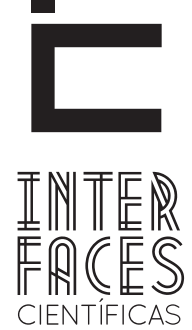

DIREITO

\title{
EXPERIÊNCIAS DE CONTROLE ESTATAL DAS RELIGIÕES NO BRASIL E EM ANGOLA
}

Kellen Josephine Muniz de Lima ${ }^{1}$
Ilzver de Matos Oliveira²

\section{RESUMO}

Em 2013, em uma decisão inédita, o governo de Angola determinou o fechamento de igrejas evangélicas neopentecostais instaladas no país sob a acusação de propaganda enganosa, o que acendeu o debate sobre o controle estatal exercido sobre a liberdade religiosa no país, especialmente a liberdade de culto. Assim, através da apresentação desse caso ocorrido em Angola e de dois outros casos processados na justiça do Brasil, o presente artigo pretende discutir a experiên- cia desses dois países com o controle fundamentalismo e a intolerância religiosa neopentecostal.

\section{PALAVRAS-CHAVE}

Fundamentalismo. Liberdade de expressão religiosa. Religiões afro-brasileiras. Igrejas neopentecostais. Controle estatal. 


\section{ABSTRACT}

In 2013, in an unprecedented decision, the government of Angola ordered the closure of neo-Pentecostal evangelical churches established in the country on charges of false advertising, which ignited the debate on the State exercised control over religious freedom in the country, especially freedom of worship. Thus, by presenting this case in Angola and two other cases may face legal action in Brazil, this article discusses

\section{RESUMEN}

En 2013 , en una decisión sin precedentes, el gobierno de Angola ordenó el cierre de las iglesias evangélicas neo pentecostales establecidas en el país bajo la acusación de publicidad engañosa , que encendió el debate sobre el control estatal ejercido sobre la libertad religiosa en el país, especialmente la la libertad de culto . De este modo, mediante la presentación de este caso en Angola y otros dos casos pueden enfrentarse a acciones legales en Brasil, en este artículo se analiza la the experience of these two countries with fundamentalism control and Pentecostal religious intolerance.

\section{KEYWORDS}

Fundamentalism. Freedom of Religious Expression. African-Brazilian Religions. Neo-Pentecostal Churches. State Control. experiencia de estos dos países con el control de fundamentalismo y la intolerancia religiosa pentecostal.

\section{PALABRAS CLAVE}

El fundamentalismo. La libertad de expresión religiosa. Las religiones afro- brasileñas. Iglesias neo pentecostales. Control del Estado. 


\section{INTRODUÇ̄̃̃O}

Recentemente, diversas pesquisas têm dado destaque a um novo fenômeno migratório religioso internacional que, principalmente nas três últimas décadas, foi (e ainda continua a ser) extremamente importante na criação, expansão, dispersão e globalização dos novos movimentos religiosos: as igrejas neopentecostais, que passaram a abranger importante e complexa relação entre o Brasil e a Europa. São essas algumas conclusões do trabalho de Braga (2013) sobre as dinâmicas e características dessa mobilidade geográfica religiosa, que o autor denomina de divine migration Pentecostal de Sul para Norte, que vem implicando em mudanças significativas no panorama religioso mundial, criando, desta forma, novas spiritual geographies.

Braga (2013) na sua investigação buscou pensar essa "exportação" religiosa e as semelhanças e diferenças entre os casos pentecostais evangélicos e católicos e como eles se inserem na perspectiva analítica da "reverse mission", ou seja, o fenômeno que explica como a Europa, que anteriormente era exportadora de instituições e doutrinas religiosas, é hoje um território fértil para o trabalho missionário.

Braga (2013), analisa que, surgidas a partir do trabalho de evangelização do Protestantismo europeu e Pentecostal norte-americano, as igrejas (neo)pentecostais latino-americanas e brasileiras consideram-se hoje responsáveis pela importante "missão divina" de (re)cristianizar a Europa, que passa por um forte processo de secularização/laicização.

Já em relação ao contexto católico europeu, com semelhante estratégia proselitista, o movimento da Renovação Carismática Católica tem por missão o reavivamento espiritual do catolicismo numa Europa secularizada, dentro da qual a Igreja Católica vem demonstrando claros sinais de perda de fiéis, e relativa diminuição de sua influência.
Para outros estudiosos, o fenômeno migratório internacional, nas últimas décadas, tem sido extremamente importante na criação e globalização de novos movimentos religiosos, abrangendo o importante triângulo Brasil-África-Europa. O modelo atual de expansão religiosa segue normalmente as diásporas emigratórias, partindo do Brasil e de países africanos de expressão portuguesa para Portugal, mas também da África lusófona para o Brasil e vice-versa, constituindo hoje um importante e global fenômeno religioso (PINEZI, 2014).

Neste artigo focaremos no estudo do movimento religioso Brasil-Angola, na mobilidade geográfica do neopentecostalismo brasileiro e nas experiências possíveis de serem compartilhadas entre os dois países para a compreensão desse fenômeno.

\section{LIBERDADE RELIGIOSA NO BRASIL}

A atual concepção do direito à liberdade religiosa apresenta uma feição nunca antes verificada, o que é perceptível quando se necessita, além de um Estado laicista para se realizá-lo, também, um Estado colaborador para tanto, posto que, no entendimento de Miranda (2000), a liberdade religiosa não se reduz a aceitação da diversidade pelo Estado, devendo este criar medidas de igualação entre as minorias religiosas e as instituições dominantes, é o que se extrai da conceituação aqui transcrita:

\begin{abstract}
A liberdade religiosa não consiste apenas em o Estado a ninguém impor qualquer religião ou a ninguém impedir de professar determinada crença. Consiste ainda, [...] em o Estado permitir ou propiciar a quem segue determinada religião o cumprimento dos deveres que dela decorrem [...]. Se o Estado, apesar de conceder aos cidadãos, o direito de terem uma religião, os puser em condições que os impeçam de a praticar, aí não haverá liberdade religiosa. (MIRANDA, 2000, p. 409).
\end{abstract}

Assim, compete também ao Estado, garantir o direito de ateus e agnósticos de terem essas opções respeitadas (opção de não crer na existência de uma 
divindade e professar a fé respectiva). Ateus e agnósticos, assim como os "religiosos", possuem o mesmo direito, garantido constitucionalmente, de não crer e de expressar a sua descrença. É o direito à liberdade de consciência.

Para Silva Neto (2008), em razão do princípio da laicidade, o Estado Brasileiro tem a obrigação de garantir e proteger o exercício pleno dos seguintes direitos derivados da liberdade religiosa e de consciência: 1) a liberdade do indivíduo de ter crença religiosa ou não; 2) a liberdade do indivíduo de professar a sua fé religiosa, caso a tenha; 3 ) a liberdade do indivíduo de trocar de religião; 4) a liberdade do indivíduo de não ser perseguido nem ofendido em razão de suas escolhas religiosas; 5) a liberdade dos familiares de decidirem pela educação religiosa, ou não, de seus descendentes; 6 ) a garantia de que esta educação religiosa não se choque com suas convicções, mas que as respeite; 7 ) a garantia de não ser discriminado em função de sua(s) crença(s).

Merece destaque aqui, quanto ao conteúdo específico do art. $5^{\circ}, \mathrm{VI}$, que a liberdade religiosa envolve, também, a crença em um determinado conjunto de valores. Portanto, a opção de um indivíduo por uma religião traz, invariavelmente, como contrapartida, o dever de observar e cumprir com alguns dogmas ou formalidades religiosas, em razão de um ato de crença: 0 indivíduo crê em um dogma ou rito específico e o segue.

Juntamente à liberdade de consciência, a Constituição de 1988, em seu art. 5 VI, traz também a liberdade de divulgação de crença, que consiste na possibilidade de o adepto professar sua crença e envidar esforços no sentido de conseguir novos fiéis, é o que se denomina proselitismo. Portanto, há, no seio da maioria das religiões (principalmente cristãs) certo dever de evangelizar, de modo que a Constituição Federal de 1988 protege, igualmente, esta dimensão coletiva, a busca por novos fiéis. Ressalte-se que este âmbito da liberdade religiosa é, também, protegido por outro direito constitucional, qual seja, a liberda- de de expressão, que em conjugação com o direito em apreço, se configura em liberdade de expressão religiosa (TAVARES, 2008).

Alexandre de Moraes (2006) explica que por se tratar de um Estado laico, dotado de uma grande diversidade de cultos religiosos, a abrangência do preceito constitucional insculpido no artigo $5^{\circ}$, VI da Constituição de 1988 é ampla, visto que "sendo a religião um complexo de princípios que dirigem os pensamentos, ações e adoração do homem para com Deus, acaba por compreender a crença, o dogma, a moral, a liturgia e o culto" (MORAES, 2006, p. 215).

Como se vê, a liberdade religiosa protege o direito de o adepto professar livremente a sua convicção, bem como de praticar e exteriorizar os dogmas e valores religiosos inerentes à sua fé. Esta proteção está presente na inviolabilidade da liberdade de crença, expressamente prevista como direito fundamental pela Constituição Federal do Brasil.

0 direito à liberdade religiosa, além de estar assegurado pela Constituição Federal de 1988, também, encontra proteção na legislação infraconstitucional (Lei no 9.394/96, Lei nº 4.898/65, Lei nº 7.716/89 etc.), bem como em Tratados Internacionais dos quais o Brasil é signatário, a exemplo da Convenção Internacional sobre Direitos Civis e Políticos; Convenção Interamericana sobre Direitos Humanos; Declaração sobre a Eliminação de todas as Formas de Intolerância e Discriminação Fundadas na Religião ou nas Convicções; Declaração sobre os Direitos das Pessoas Pertencentes a Minorias Nacionais ou Étnicas, Religiosas e Linguísticas; a Declaração de Princípios sobre a Tolerância.

Consoante se percebe, o Brasil dispõe de um robusto arcabouço constitucional e infraconstitucional de proteção ao direito fundamental à liberdade religiosa. Todavia, em que pese à existência de vasta legislação protetiva, ainda são muitos os casos de intolerância e violência no campo religioso, principalmente, praticadas em desfavor das religiões afro-brasileiras. Assim, 
a apresentação de alguns casos emblemáticos de intolerância religiosa (enfrentados pelo judiciário), será o fio condutor que nos permitirá analisar as rotas de colisão em que se situam diversas categorias de direitos envolvidas neste fenômeno social.

\section{LIBERDADE RELIGIOSA EM ANGOLA}

A Constituição da República de Angola, em seu Artigo $10^{\circ}$, define o país como um Estado laico, com separação entre a Igreja e o Estado, bem como reconhece e respeita as diferentes confissões religiosas, que são livres na sua organização e no exercício das suas atividades, desde que as mesmas se conformem à Constituição. Seu art. $41^{\circ}$ prevê a liberdade de consciência, de religião e de culto, ou seja, garante que ninguém pode ser privado dos seus direitos, discriminado, perseguido ou isento de obrigações por motivo de crença religiosa (CONSTITUIÇÃO DA REPÚBLICA DE ANGOLA, 2010).

Além da Constituição, vigora também a Lei nº 2/4 sobre o Exercício da Liberdade de consciência, culto e Religião. 0 art. $9^{\circ}$ da referida lei determina que as confissões religiosas somente obtêm personalidade jurídica mediante reconhecimento feito pelo Governo, por meio do Ministério da Justiça, com o parecer favorável do Ministério da Cultura. O requerimento para obtenção da personalidade jurídica é dirigido ao Ministério da Justiça e deve ser subscrito por um número mínimo de 100 mil fiéis maiores e com domicílio em território nacional, devendo as assinaturas ser reconhecidas notarialmente e recolhidas num mínimo de 2/3 do total das províncias, ou seja, 12 das 18 províncias do território angolano. Apenas os grupos oficialmente registrados têm direito a fundar escolas e edifícios para o culto (BARROS, 2015).

A edição de 2014 do relatório da Fundação Ajuda à Igreja que Sofre (AIS), organização da Igreja Católica, analisou a situação da liberdade religiosa em Angola (e outros 196 países, incluindo o Brasil) no período en- tre outubro de 2012 e junho de 2014, e concluiu que alguns grupos religiosos minoritários se queixam do favoritismo do governo angolano em relação à Igreja Católica. 0 relatório, também, destacou a existência de queixas de discriminação governamental e propaganda negativa por parte da comunidade muçulmana (FUNDAÇÃO..., 2014).

A Comunidade Islâmica de Angola (COIA) acusa as autoridades angolanas de perseguirem o Islão e de ordenarem o fechamento de mesquitas (das estimadas 78 mesquitas no país, 60 tiveram as portas fechadas, exceto as da capital Luanda). Quanto à acusação de perseguição religiosa, o governo nega e justifica a rejeição dos pedidos de registro apresentadas por várias comunidades muçulmanas, bem como a destruição de algumas mesquitas, na falta de cumprimento da lei (JARDIM, 2013).

O relatório da AIS (2014), também, aponta a ridicularização pública e ataques em campanhas de sensibilização oficiais a algumas práticas animistas, descritas como feitiçaria, bem como a vandalização de santuários e imagens católicas por elementos ligados a grupos evangélicos (FUNDAÇÃO..., 2014).

Percebe-se, portanto, que de modo geral a liberdade religiosa é garantida constitucionalmente pelo ordenamento jurídico angolano, contudo, o exercício amplo e irrestrito, especialmente da liberdade de culto, é controlado pelo Estado, que restringe a livre abertura de congregações religiosas impondo rigorosas exigências para obtenção do reconhecimento legal necessário ao funcionamento, resultando numa efetiva negação do direito à liberdade de culto de alguns grupos religiosos minoritários.

Apesar das rigorosas exigências por parte do Governo Angolano, igrejas evangélicas brasileiras, notadamente as neopentecostais, a exemplo da Igreja Universal do Reino de Deus (IURD) e a Igreja Mundial do Poder de Deus, abriram filiais naquele país, que conta com cerca de $15 \%$ de população evangélica. A IURD, 
apenas para citar como exemplo, chega a contar com 500 mil seguidores (FELLET, 2013).

\section{CONTROLE JUDICIAL DO FUNDAMENTALISMO NO BRASIL: LIBERDADE RELIGIOSA X LIBERDADE DE EXPRESSÃO: 0 CASO MINISTÉRIO PÚBLICO DA BAHIA X LIVRO “ORIXÁS, CABOCLOS \& GUIAS", DO BISPO EDIR MACEDO}

A judicialização de casos, envolvendo o abuso da liberdade de expressão religiosa na mídia brasileira merece destaque. Neste aspecto, se sobressai a conduta deliberada de parte do segmento evangélico ao fazer uso da concessão pública de mídia televisiva para disseminar, em nome da liberdade religiosa, discursos de ódio pautados na ofensa gratuita às religiões de matriz africana e aos seus seguidores, reforçando a intolerância, a estigmatização, o preconceito e a discriminação.

A "tragédia do Charlie Hebdo", forma como ficou conhecido o recente atentado terrorista deflagrado contra a sede da revista francesa "Charlie Hebdo", ocorrido no dia 7 de janeiro de 2015, que deixou 12 mortos e 11 feridos, chocou o mundo e reacendeu a discussão sobre os limites da liberdade de expressão da imprensa, especialmente quando essa liberdade de expressão adentra nos limites dos territórios da fé. A autoria do atentado recaiu sobre europeus jihadistas e seria uma resposta contra as charges satíricas (tendo por alvo constante o profeta Maomé e o islamismo) publicadas frequentemente (INTERVOZES, 2015).

A partir deste episódio ficou a seguinte indagação: Vale tudo em nome da liberdade de expressão?

Para refletir sobre essa pergunta, analisaremos, como um dos exemplos de controle estatal das religiões no Brasil, a Ação civil pública proposta pelo Ministério Público Federal da Bahia para proibir a venda em todo o Brasil do livro "Orixás, Caboclos e Guias Deuses ou Demônios?", escrito pelo bispo Edir Macedo, um dos fundadores da Igreja Universal do Reino de Deus.

A ação civil pública no 2005.33.00.022891-3, em trâmite na $4^{a}$ Vara Federal da Seção Judiciária da Bahia, foi proposta pelo Ministério Público da Bahia em 3 de novembro de 2005, tendo como réus Edir Macedo, a Igreja Universal do Reino de Deus e a Gráfica Universal Ltda., responsáveis pela publicação, vendagem e distribuição gratuita da obra Orixás, Caboclos e Guias, deuses ou demônios?

Visto pelo Ministério Público da Bahia como de conteúdo preconceituoso e discriminatório, o escritor Edir Macedo, na referida obra, afirma seu desejo antigo de colocar em um livro toda a verdade sobre os orixás, caboclos e os mais diversos guias, que vivem enganando as pessoas e fazendo delas "cavalos", "burrinhos" ou “aparelhos" (MACEDO, 2004, p. 9). Segundo o autor, os deuses cultuados pelas religiões afro-brasileiras representam "anjos decaídos", "demônios" e a "personificação do mal” (MACEDO, 2004, p. 24).

Ao longo do texto são abordadas outras expressões que incitam o ódio, tais como: "pise na cabeça dos exus", "parta para cima dos exus, caboclos", "a Igreja tem de agir". Ainda, no livro, atribui-se o subdesenvolvimento do Brasil a tais cultos, como também se associa o "pecado mortal" às religiões de matriz africana (BRASIL, 2005, p. 7).

O Ministério Público Federal, na referida Ação Civil Pública, sustenta que a intolerância religiosa estampada no livro se enquadra na tipificação dos crimes previstos do artigo 20 da Lei no 7.716/89 (preconceito de religião) e do artigo 208 do Código Penal (ultraje a culto e impedimento ou perturbação de ato a ele relativo), visto que incita os leitores, por meio de um discurso de ódio, ao preconceito e discriminação frente às religiões afro-brasileiras. Também sustenta que havendo conflito entre o direito de liberdade religiosa e de expressão esta última não se mostra absoluta e preponderante. 
Liminarmente, o Ministério Público pediu a imediata retirada de circulação, suspensão de tiragem, venda, revenda e entrega gratuita da obra em questão. Como pedido principal, requereu a condenação dos réus à suspensão definitiva da obra (BRASIL, 2005, p. 14).

0 pedido em liminar foi deferido pela juíza da $4^{a}$ Vara Federal da Subseção da Bahia, em 8 de novembro de 2005, que corroborou com as afirmações constantes da inicial, reconhecendo que a obra é, de fato, marcada por disseminação de ideias segregacionistas e discriminatórias de cunho religioso e ultrapassa os limites da liberdade religiosa ao não cingir-se apenas à explanar e divulgar a religião de Edir Macedo, mas ao tratar pejorativamente outras religiões e seus adeptos (BRASIL, nov. 2005).

A decisão da referida juíza federal retrata o livro como sendo abusivo e atentatório ao direito fundamental da sociedade, que tem direito à convivência harmônica e fraterna, a despeito de toda a sua diversidade (de cores, raças, etnias e credos); acrescenta, também, que a ordem constitucional vigente proíbe a difusão de opiniões como as insertas na obra,

[...] dado que a orientação lá contida como que 'sai do contexto da própria religião', enquanto conjunto de princípios, preceitos e interpretações, e ingressa na órbita trilhada por outra religião [...] desacreditando-a e depreciando-a perante a sociedade, a ponto de ser ofensiva a seus adeptos. (JFBA, 2005, p. 9).

Neste sentido, segue o dispositivo da decisão da $4^{\mathrm{a}}$ Vara Federal da Subseção da Bahia, que deferiu a liminar pleiteada pelo Ministério Público Federal:

[...] Por tais fundamentos, defiro a liminar tal qual requerida pelo Autor, pelo que, determino, aos demandados, que promovam, em todo o território nacional, a imediata retirada de circulação, suspensão de tiragem, venda, revenda e entrega gratuita (seja em igrejas, templos, entreposto, livrarias ou serviço de "televendas"- 0300, 0800 ou equivalente) da obra "Orixá, Caboclos e Guias, deuses ou demônios?”, de autoria do réu Edir Macedo, bem como o recolhimento de todos os exemplares existentes em estoque, no prazo de 30 (trinta) dias, sob pena de incursão em multa diária fixada no valor de $\mathrm{R} \$ 50.000,00$ (cinquenta mil reais), sem caso de descumprimento, além das sanções cíveis e criminais cabíveis. (JFBA, 2005, p. 10).

Entretanto, no ano de 2006, após análise do Recurso de Agravo de Instrumento interposto pela defesa de Edir Macedo, os desembargadores do Tribunal Regional Federal da $1^{\text {a }}$ região liberaram a vendagem do referido livro. A Turma entendeu que a obra, de fato, contém expressões e mensagens preconceituosas, mas que deve prevalecer a liberdade de pensamento aventada pelo artigo $5^{\circ}$ da Constituição. 0 relator do acórdão, Desembargador Leão Aparecido, ressaltou que a questão suscita um descompasso entre artigos da constituição - enquanto se defende a liberdade de expressão e se proíbem apologias de cunho racial ou religioso - contudo, o autor tem o direito garantido pela Constituição de expressar seu pensamento e, ademais, a obra está restrita a um grupo de interessados, ligados àquela profecia de fé (JUSBRASIL, 2006).

Conforme últimas informações sobre o processo disponíveis no sítio eletrônico da Justiça Federal da Bahia, no ano de 2009 foi proferida decisão pelo Tribunal Regional Federal da $1^{a}$ Região, reconhecendo a incompetência da justiça federal e determinando a remessa dos autos à justiça estadual da Bahia. Infelizmente, após intensa pesquisa realizada junto à página eletrônica do referido Tribunal, não foi possível localizar o inteiro teor do Acórdão relativo a esta decisão. Em razão de tal remessa, foi gerado o processo $n^{0}$ 0004170-51.2010.8.05.0001, com trâmite na $23^{a}$ Vara dos Feitos de Rel. de Cons. Civ. e Comerciais - Salvador, que está concluso para despacho do juiz, Dr. Eduardo Augusto Viana Barreto, desde 30/10/2012 (BAHIA, 2010).

Em decorrência da revogação da liminar concedida pela $4^{a}$ Vara Federal de Salvador, a obra Orixás, Caboclos e Guias, deuses ou demônios? voltou a ser distribuída pela Igreja Universal do Reino de Deus. 


\section{5 "ODIA DO FIM": GOVERNO ANGOLANO XIGREJAS NEOPENTECOSTAIS}

Um episódio trágico ocorrido em 31 de dezembro de 2012 abalou a relação harmoniosa que, até então, era mantida entre o governo angolano e as igrejas neopentecostais. Trata-se da morte de 16 pessoas por asfixia e esmagamento durante um culto da Igreja Universal do Reino de Deus em Luanda. 0 culto reuniu $150 \mathrm{mil}$ pessoas no estádio da Cidadela, cuja capacidade original seria de apenas 30 mil pessoas, atraídas pelo que foi denominado como "O Dia do Fim", cuja propaganda prometia dar um fim a todos os problemas tais como: doença, miséria, desemprego, feitiçaria, inveja, problemas na família, separação, dívidas etc. (FELLET, 2013).

O Governo investigou o caso e concluiu que a superlotação no estádio, e respectivas mortes, teve como causa a prática de "publicidade enganosa" por parte da Igreja Universal que, assim como outras igrejas evangélicas brasileiras, "se aproveitam das fragilidades do povo angolano" (MELLO, 2013, [s.p.). Como resultado da investigação, em fevereiro de 2013 o governo ordenou a suspensão das atividades da IURD por 60 (sessenta) dias. Tal suspensão se estendeu a outras seis igrejas evangélicas (dentre as quais três brasileiras, incluindo a Igreja Mundial do Poder de Deus), por, segundo o governo, recorrerem "às mesmas práticas que as da IURD” e operarem sem licença no País (FELLET, 2013).

Semelhante ao que acontece no Brasil, a IURD em Angola, também, utiliza discursos que perpassam pela propaganda enganosa, vendendo aos fiéis a promessa de soluções e curas milagrosas para todos os males. Do mesmo modo, também, adota discursos intolerantes e eivados de preconceito, motivo pelo qual, assim como no Brasil, entre antropólogos e estudiosos de religiões, é comum a crítica de que a Universal, e outras igrejas neopentecostais, estigmatizam crenças de origem africana e contribuem para que sejam tão discriminadas (FELLET, 2013).
Contudo, em março de 2013 o governo angolano revogou a suspensão da Igreja Universal, permitindo que retomasse seu funcionamento sob fiscalização dos ministérios do Interior, Cultura, Direito Humanos e Procuradoria Geral da Justiça. A suspensão das outras igrejas brasileiras, ainda, permanece por falta de reconhecimento oficial do Estado angolano. Segundo o governo, essas igrejas estavam realizando propaganda enganosa e se aproveitando das fragilidades do povo, funcionando como um verdadeiro negócio de venda de milagres (MELLO, 2013).

Como resultado da proibição, a Igreja Universal do Reino de Deus, que possui 230 templos e cerca de 500 mil fiéis em Angola, passou a ser a única oficialmente autorizada pelo governo, apesar de funcionar sob intervenção, garantindo, assim, monopólio e sua reserva de mercado entre as igrejas evangélicas neopentecostais brasileiras naquele país.

A partir do cenário apresentado e traçando um comparativo com os casos judiciais emblemáticos apontados neste trabalho, que demonstram a experiência brasileira com a intolerância religiosa praticada pelas igrejas neopentecostais, especialmente a Igreja Universal do Reino de Deus, é possível perceber semelhanças concretas entre as estratégias de marketing religioso e de estigmatização das crenças africanas utilizadas pela IURD (como também pelas demais igrejas neopentecostais) tanto no Brasil quanto em Angola. Em ambos os países vemos a repetição dos mesmos padrões de discurso que pregam intolerância e a promessa de obtenção de curas e soluções milagrosas.

Diferente do que acontece em Angola, contudo, no Brasil a liberdade religiosa é ampla, geral e irrestrita, garantida como direito fundamental pela Constituição Federal de 1988, não sendo possível uma intervenção estatal a ponto de determinar o fechamento de congregações religiosas. Cabe, portanto, ao Ministério Público, como fiscal da lei brasileira que é provocar o judiciário, por meio do manejo das 
ações judiciais competentes, a fim de que abusos e arbitrariedades não sejam cometidos em nome desta liberdade religiosa.

Convém refletir, entretanto, se não caberia também ao governo brasileiro, não apenas ao Ministério Público, operar uma fiscalização mais direta e efetiva sobre o funcionamento dessas igrejas que propagam discursos de intolerância e ódio por meio do uso das concessões públicas de rádio e TV, bem como se utilizam de marketing enganoso, voltado a ludibriar fiéis com promessas de soluções e curas milagrosas.

Não estamos com isso, pregando a utilização do modelo intervencionista angolano, mas refletindo sobre as consequências advindas da total inércia dos órgãos e agentes estatais brasileiros, a exemplo dos ministérios das Comunicações, da Cultura e Secretaria de Direitos Humanos, que permitem a continuidade do uso das concessões públicas de rádio e TV, como instrumento de afronta à manutenção de um espaço público democrático que assegure a liberdade de consciência e a diversidade de pensamento. Se as emissoras de televisão e rádio são concessionárias do serviço público federal de radiodifusão, devem compatibilizar sua atuação com preceitos fundamentais como o direito à honra e a não discriminação. É responsabilidade de o governo brasileiro operacionalizar essa fiscalização.

Em se tratando do direito à liberdade religiosa de maneira ampla, portanto, se por um lado, para o sistema jurídico constitucional brasileiro, a postura intervencionista do governo angolano parece desrespeitar a ordem constitucional estabelecida, que garante a liberdade religiosa como direito fundamental do ser humano, por outro lado, talvez a postura do governo brasileiro, que se mantém inerte, contando exclusivamente com a atuação do Ministério Público nos casos de intolerância e abuso da liberdade de expressão, praticados repetidamente pelas igrejas neopentecostais, seja excessivamente tímida.

\section{CONCLUSÃO}

Com base no que foi discutido no presente trabaIho, constatou-se que a Constituição Federal de 1988 trouxe significativas contribuições para a proteção do livre exercício das crenças e cultos existentes no Brasil, país laico e democrático. Aliados, à garantia constitucional encontramos, também, outros dispositivos infraconstitucionais, bem como vários outros documentos internacionais dos quais o Brasil é signatário.

Entretanto, o exercício pleno deste direito fundamental por parte de minorias religiosas, a exemplo das religiões de matriz africana, encontra sérios obstáculos em razão da prática de intolerância perpetrada, principalmente, pelos evangélicos neopentecostais contra os adeptos dessas religiões. Os recorrentes episódios de violência e discurso de ódio religioso colocam em pauta a existência de questões ainda não resolvidas pelo Estado Democrático de Direito, relativas ao exercício pleno das garantias constitucionais.

O fenômeno da judicialização dos conflitos, envolvendo casos de intolerância religiosa se mostra como uma reação pública dos adeptos das religiões de matriz africana que recorrem ao Judiciário, enquanto agente estatal capaz de garantir a efetividade de seus direitos fundamentais, sobretudo, a liberdade religiosa em seu sentido pleno. A partir dessa judicialização, surgiram casos emblemáticos, tais como as diversas ações civis públicas propostas pelo Ministério Público, buscando ressarcimento por dano moral em razão da incitação do ódio e intolerância contra religiosos afro-brasileiros, especialmente pelos segmentos evangélicos neopentecostais.

Vimos, em muitos dos casos emblemáticos apresentados, questões processuais que prejudicaram a análise efetiva do mérito das demandas. Ressoa, portanto, a necessidade cada vez mais crescente de um real enfrentamento por parte do judiciário, para fins de garantir e concretizar o pleno exercício do direito fundamental dos adeptos das religiões afro-brasileiras. 
Semelhante ao que acontece no Brasil, Angola também vive um momento de expansão do segmento evangélico, especialmente neopentecostal, de modo que diversas igrejas brasileiras instalaram filiais naquele país. Essas igrejas neopentecostais em Angola, assim como no Brasil, também, utilizam discursos intolerantes e eivados de preconceito que estigmatizam crenças de origem africana. Contudo, diferente do Brasil, o exercício amplo e irrestrito especialmente da liberdade de culto é controlado pelo governo angolano, que restringe a livre abertura de congregações religiosas, impondo rigorosas exigências para obtenção do reconhecimento legal necessário ao funcionamento.

Atualmente, dentre as igrejas evangélicas brasileiras, apenas a Igreja Universal do Reino de Deus está autorizada pelo governo angolano a funcionar no país, contudo, sob fiscalização de suas atividades com vistas a evitar, ao menos é este o discurso oficial adotado, a repetição de práticas enganosas por meio das quais a igreja tire proveito da fragilidade de seus fiéis.

Diferente do exemplo brasileiro, que mesmo com ao ajuizamento de inúmeras ações civis públicas pelo Ministério Público com vistas a obter a devida responsabilização das igrejas neopentecostais, especialmente da Igreja Universal, e coibir os repetidos abusos cometidos na utilização das concessões públicas de rádio e TV, consegue apenas vitórias parciais e pouco expressivas no judiciário brasileiro, em Angola a intervenção se faz por via direta, por meio do próprio governo estatal.

Evidente que adoção do modelo intervencionais angolano seria impossível no Brasil, dada a sua incompatibilidade com o texto normativo da Constituição Federal de 1988, e não é isso que se pretende propor nestas linhas. Contudo, merece reflexão a excessiva falta de fiscalização que se opera no Brasil, em que o governo estatal permite que concessões públicas de rádio e TV sejam utilizadas diariamente como instrumentos de propagação de discursos de ódio e intolerância que fere, persegue e estigmatiza camadas minoritárias da sociedade, o que não condiz com a função constitucional da comunicação social.

Cabe ao Estado assegurar a efetividade dos direitos fundamentais, seja a liberdade religiosa ou a liberdade de expressão, sem permitir abuso de direito por qualquer dos lados, com vistas à manutenção de um espaço público democrático que assegure a liberdade de consciência e a diversidade de pensamento.

\section{REFERÊNCIAS}

\section{ANGOLA. Constituição da República de Angola de}

2010. Disponível em: <http://www.governo.gov.ao/ Arquivos/Constituicao_da_Republica_de_Angola. pdf>. Acesso em: 9 mar. 2015.

BAHIA. Tribunal de Justiça (TJBA). ACP n. 000417051.2010.8.05.0001. 23a Vara dos Feitos de Rel. de Cons. Civ. e Comerciais. Juiz: Eduardo Augusto Viana Barreto. Salvador, BA. 2010. Disponível em: <http:// www5.tjba.jus.br/>. Acesso em: 10 jan. 2015.

BARROS, Manuel. 0 direito a liberdade religiosa. Centro de Ajuda Académica, Luanda, 4 fev. 2015. Disponível em: <http://ajudaacademica.info/opiniao/o-direito-liberdade-religiosa/>. Acesso em: 9 mar. 2015.

BARROSO, Luís Roberto. Constituição, democracia e supremacia judicial: direito e política no Brasil contemporâneo. Salvador: JusPODIVM, 2011.

BRAGA, Antônio Mendes da Costa. A Renovação Carismática Católica brasileira na Europa: o fenômeno da "reverse mission". São Paulo: UNESP, 2013.

BRASIL. Constituição da República Federativa do

Brasil de 1988. Disponível em: <http://www.planalto. gov.br/ccivil_03/constituicao/constituicaocompilado. htm>. Acesso em: 12 jan. 2015. 
BRASIL. Justiça Federal da Bahia (JFBA). ACP $\mathbf{n}^{\mathbf{0}}$ 2005.33.00.022891-3. $4^{a}$ Vara Federal. Juíza: Nair Cristina C. P. de Castro. Salvador, BA. 8 nov. 2005. Disponível em: <http://www.prba.mpf.mp.br/paraocidadao/pecas-juridicas/acoes/liminar_universal_.pdf/ view>. Acesso em: 12 jan. 2015.

BRASIL. Ministério Público Federal (MPF). Petição Inicial Ação Civil Pública n. 2005.33.00.0228913. $4^{\mathrm{a}}$ Vara Federal da Bahia. 2005. Disponível em: <http://www.prsp.mpf.gov.br/prdc/area-de-atuacao/digualdetnraclibrel/Acao\%20Civil\%20 Publica\%20-\%20Livro\%20da\%20Igreja\%20Universal\%20do\%20Reino\%20de\%20D.pdf/view>. Acesso em: 12 jan. 2015.

CARVALHO, Luis Gustavo Grandinetti Castanho de. Direito de Informação e liberdade de expressão. Rio de Janeiro: Renovar, 1999.

CHELIKANI, Rao V. B. J. Reflexões sobre a tolerância/ Rao V. B. J. Chelikani; tradução e revisão Catarina Eleonora F. da Silva, Jeane Sawaya. Rio de Janeiro: Garamond, 1999.

COMISSÃO DE COMBATE A INTOLERÂNCIA RELIGIOSA - CCIR/RJ. Relatório à ONU. Rio de Janeiro, 2009. Disponível em: <http://ccir.org.br/downloads/relatorio_onu.pdf>. Acesso em: 7 jan. 2015.

COSTA, Maria Emília Corrêa da. Apontamentos sobre a liberdade religiosa e a formação do Estado Laico. In: LOREA, Roberto Arriada (org.). Em Defesa das Liberdades Laicas. Porto Alegre: Livraria do Advogado, 2008. p.97-116.

DOMINGOS, Marília de Franceschi Neto. Laicidade: o direito à liberdade. Horizonte: Dossiê: Laicidade, Estado e Religião, v.8, n.19, Belo Horizonte, out./dez. 2010. p.53-70.

ECO, Umberto. A Intolerância. Rio de Janeiro: UNESCO; Bertrand Brasil, 2000.
FELLET, João. Suspensão põe em xeque expansão de igrejas evangélicas em Angola. BBC Brasil, Brasília, 7 fev. 2013. Disponível em: <http://www.bbc.co.uk/ portuguese/noticias/2013/02/130207_angola_evangelicos_jp_jf.shtml>. Acesso em: 10 mar. 2015.

FUNDAÇÃO Pontifícia Ajuda à Igreja Que Sofre - AIS. Liberdade religiosa no mundo: Relatório 2014. São Paulo, 2014. Disponível em: <http://ais.org.br/RelatorioLiberdadeReligiosa/pdf/Angola.pdf>. Acesso em: 9 mar. 2015.

GIUMBELLI, Emerson. 0 fim da religião: dilemas da liberdade religiosa no Brasil e na França. São Paulo: Attar, 2002.

INTERVOZES. 0 atentado ao Charlie Hebdo e a regulação da mídia. Carta Capital, São Paulo, 11 jan. 2015. Disponível em: <http://www.cartacapital.com.br/blogs/intervozes/o-atentado-contra-o-charlie-hebdo-e-a-regulacao-da-midia-na-franca-e-no-brasil-3015. html>. Acesso em: 16 jan. 2015.

JARDIM, Camila. Angola aperta cerco contra a comunidade islâmica. 0 Globo, Rio de Janeiro, 30 nov. 2013. Disponível em: <http://oglobo.globo.com/mundo/angola-aperta-cerco-contra-comunidade-islamica-10929683>. Acesso em: 9 mar. 2015.

JUSBRASIL. Expresso da Notícia. TRF libera circulação do livro de Edir Macedo. 2006. Disponível em: <http://expresso-noticia.jusbrasil.com.br/noticias/136368/trf-libera-circulacao-do-livro-de-edir-macedo>. Acesso em: 12 jan. 2015.

KOATZ, Rafael Lorenzo-Fernandez. As Liberdades de Expressão e de Imprensa na Jurisprudência do STF. In: SARMENTO, Daniel; SARLET, Ingo Wolfgang (orgs.). Direitos Fundamentais no Supremo Tribunal Federal: Balanço e Crítica. Rio de Janeiro: Lúmen Júris, 2011.

LIMA, Francisco Gérson Marques de. O STF na crise institucional brasileira. São Paulo: Malheiros, 2009. 
LOCKE, John. Carta a respeito da tolerância. Lisboa, Portugal: 70, 1987.

MACEDO, Edir. Orixás, Caboclos e Guias: Deuses ou Demônios? Rio de Janeiro: Gráfica Universal, 2004.

MELLO, Patrícia Campos. Angola proíbe operação de igrejas evangélicas do Brasil. Folha de S. Paulo, São Paulo, 27 abr. 2013. Disponível em: <http://www1. folha.uol.com.br/mundo/2013/04/1269733-angola-proibe-operacao-de-igrejas-evangelicas-do-brasil. shtml>. Acesso em: 10 mar. 2015.

MIRANDA, Ana Paula Mendes de. Entre o privado e o público: considerações sobre a (in) criminação da intolerância religiosa no Rio de Janeiro. Anuário antropológico/2009-2, 2010. p.125-152.

MIRANDA, Jorge. Manual de Direito Constitucional. Tomo IV, direitos fundamentais. 3.ed. Coimbra: Coimbra, 2000.

MONTES, Maria Lucia. As figuras do sagrado: entre o público e o privado. História da vida privada no Brasil: contrastes da intimidade contemporânea. 6.reimpressão, v.4. São Paulo: Companhia das Letras, 1998.

MORAES, Alexandre de. Constituição do Brasil Interpretada. 6.ed. São Paulo: Atlas, 2006.

Recebido em: 25 de Março de 2015 Avaliado em: 2 de Abril de 2015 Aceito em: 9 de Abril de 2015
MORAES, Alexandre de. Direito Constitucional. 10.ed. São Paulo: Atlas, 2004.

OLIVEIRA, Ilzver de Matos; ALVES, Robson Cosme de Jesus. Liberdade religiosa versus liberdade de expressão: violações aos direitos humanos dos religiosos de matriz africana nos meios de comunicação de massa no Brasil. Interfaces Científicas: Direito, Aracaju, v.1, n.1, fev. 2013. p.85-94.

ORTIZ, Renato. A morte branca do feiticeiro negro: umbanda e sociedade brasileira. São Paulo: Brasiliense, 1999.

SANTOS, Boaventura de Sousa. A Europa à beira do estado de sítio. Outras Palavras, São Paulo, 14 jan. 2015. Disponível em: <http://outraspalavras.net/ capa/boaventura-a-europa-a-beira-do-estado-de-sitio/>. Acesso em: 16 jan. 2015.

SILVA NETO, Manoel Jorge e. Proteção Constitucional à Liberdade Religiosa. Rio de Janeiro: Lumen Juris, 2008.

SILVA, Vagner Gonçalves da. Intolerância religiosa: impactos do neopentecostalismo no campo religioso afro-brasileiro. São Paulo: EDUSP, 2007.

TAVARES, André Ramos. Curso de Direito Constitucional. 6.ed. São Paulo: Saraiva, 2008.

1. Mestranda em Direitos Humanos pela Universidade Tiradentes. Estudante-pesquisadora do Grupo de Pesquisa Políticas Públicas de Proteção aos Direitos Humanos - UNIT-CNPq. E-mail: kellen_muniz@yahoo.com.br 2. Pós-doutorando no Centro de Estudos Sociais da Universidade de Coimbra - CES. Doutor em Direito PUCRio. Professor do Mestrado em Direito da Universidade Tiradentes. Vice-Líder do Grupo de Pesquisa Grupo Políticas Públicas de Proteção aos Direitos Humanos - UNIT-CNPq.

E-mail: ilzver@gmail.com 